\title{
A Quantitative Approach Analysis on Subject-Verb Agreement Problem Among English as Second Language Learners: A Case Study of Pakistani Students
}

\author{
Rafia Alyas
}

\begin{abstract}
Subject-verb agreement violation has been one of the major problem in L2 learners' writings. This piece of paper seeks to take a brief look into writings of Pakistani origin L2 learners and find out the mistakes related to subject-verb agreement. The data for the study has been taken from ICNALE (International Corpus Network of Asian Learners of English), a platform that gathered the responses of learners from ten Asian countries and English natives. Only Pakistani learners' data has been considered for the present study. Responses to a question, "Is it important for the college students to have a part-time job?" have been taken for analysis. Overall mode of the study is quantitative. Moreover, further researchers can be done by comparing the data of all Asian countries' learners for this feature and other language feature.
\end{abstract}

Keywords: Subject-verb agreement, ICNALE, L

DOI: $10.7176 / J L L L / 56-01$

Publication date:May $31^{\text {st }} 2019$

\section{Introduction}

A non-native language learning is a long-lasting practice and it is frequently a challenging experience for nonnatives. Currently, English is a global communication-language which is used in exchanging knowledge and in foreign dealings. It has been only since a few decades ago that it is taught to almost all students. In general local Pakistani students spend almost twelve years of learning English in schools and colleges. In written English, the subject-verb agreement has always remained the major problem for second-language-learners. Many researchers have done a lot of work on it and. Different authors gave different definitions of subject-verb agreements depending on the types of errors occurred by the students. According to Rebecca Elliott (2006): A singular subject needs a singular verb, and a plural subject needs a plural verb. "According to Keenan (1975): "When the subject of the sentence is a phrase, the following verb must agree with the main noun in the subject." According to Michael Strumpf and Auriel Douglas (2004): Subjects connected by and almost always form a plural subject and demand a plural verb. If the subject contains coordinated noun phrases, the agreement is usually with the second noun phrase when the two phrases differ in number. This research also relates to subject-verb agreement errors and their solutions. It is mostly based on the Rebecca Elliott definition, a singular verb comes with singular subject and a plural verb comes with plural object. Other definitions are also considered during the analysis of data.

\section{Literature Review}

Studies by Dr. Amina Go-go Tafida and Dr. Shittu Kelani Okunade, the researchers figured out (2016) on English Subject-Verb Agreement problem among English as second language learners in Minna (A city in westcentral Nigeria). This was a corpus-based study. For this research, the researcher conducted the essay test of one hundred and twenty students of the Federal University of Technology, Minna. These students were registered for GST 2k14/2k15 academic session. They took over forty minutes to compose an essay. Essays were classified into four parts and broke down on the basis of these categories. Areas which are identified in these categories are based on SVA problems. These areas are Nouns, Pronouns, Tense and Intervening Expressions. For having linguistic features, the researcher used online-software to count frequencies. This study resulted that the pronouns have more error frequencies (142) accompanied by tens (107), nouns (65) and errors involving intervening variables (64). The survey also concluded that pupils should gain more sense about the subject-verb agreement in the input surrounds them. So that, they use the second language in a natural manner.

Saadiyah Darus (2009) worked on the error analysis of the written English essays of secondary school students in Malaysia. This was a corpus-based study. For the research, the researcher took the essay test about seventy-two students, in which thirty-seven males and thirty-five females participated. These students studied in the secondary school in Malaysia. The instruments which were utilized by the researcher for this purpose are participants, written essays, and Markin software. The mistakes committed by students in essay writing were identified and classified. The outcomes showed that the six most common errors committed by the students were singular/plural form, verb tense, verb choice, preposition, subject-verb agreement and word order. The researcher also threw light on the ways in which students internalize the target language.

Muhammad Syaifurrahman and M. Zaini Miftah (2016) also found the types of errors and the factors of 
errors which caused subject-verb agreement mistakes in diary writing by the second-semester students of the English Department. The quantitative approach had been taken up by the researcher and the analysis was based on the surface analysis taxonomy. The tools which were used for data collection are writing test, writing task, interview and documentation. The subject of the research was those three students who secured lowest marks in writing test. These students had the task to write diaries two times in a week. The researcher found 52 subjectverb agreement errors in their diaries. These errors were classified into three types on the base of surface strategy taxonomy. Granting to the research 14 errors in misformation, 19 errors in addition, and 19 mistakes in omission had been found. The subject-verb agreement errors in the diaries were caused by 40 intralingual transfers and 12 interlingual transfers.

In recent experimental research Hameedullah Khan (2017) also worked on the errors in sentence patterns, especially in SVO and SVA chain. In his quantitative research, the researcher did the pretest experiment on the intermediate level students and identified the errors. After taking the test, some instructions related to SVO and SVA were given to the students and then a post-test was constructed. The researcher analyzed that students overcome the errors after the instructions.

In 2015, Samuel Drew Ascoli from Iowa State University worked on the errors in a group of subject-verb agreement. He focused that, in what way the two NP occur in a sentence according to its verb as a singular or plural noun. The research had been directed to describe SVA with the group of NP and number of NP and NP similar to it as a way of shrinking the gap between grammatical descriptions of the phenomenon and it's coaching to non-native speakers of English. This was the corpus-based study. The approach used by the researcher was quantitative approach. The data had been extracted from the Corpus of Contemporary American English (COCA). Using the data, individual features had been studied such as modifiers and determiners with respect to their division with singular or plural-agreeing-verbs to find the trends and new patterns of an agreement. Thus, this study laid the foundation for further studies of quantification in semantics, grammar, and cognition.

4.1-Main Objective of the Research:

1. To identify the area in which the second-language learners do most mistakes in writing.

2. To identify the noun errors.

3. To identify the helping verbs, which are omitted and used incorrectly by students.

4.2-Research Questions:

1. In which area second language learners do most mistakes?

2. What type of noun errors are committed by the students?

3. Why students omit or use incorrectly the helping verb in writings?

4.3-Methodology

The essays written on 'part time job' of eighteen Pakistani students have been taken as the sample subject of the research. These sample essays have been taken from the ICNALE to identify the subject-verb agreement problems in written essays. All the essays read manually and are mainly classified in four types of subject-verb agreement errors which are noun errors, tense errors, subject errors and verb omitting errors.

1- Tense mistakes in subject-verb agreement: A singular verb comes with singular subject and a plural verb comes with plural object.

2- Errors in subject dealings according to the given verb.

3- Noun Errors

4- Students omitted the helping verb from the sentence and also used helping verbs incorrect

\section{Analysis of sample data}

5.1-Tense mistakes in subject-verb agreement: A singular verb comes with singular subject and a plural verb comes with plural object.

1) Wrong: They does not want to make a burden on their parents.

Correct: They do not want to make a burden on their parents.

2) Wrong: They helps her husband to increase her family income through their job. Some women teaches students in their homes in the evening time.

Correct: They help her husband to increase her family income through their job. Some women teaches students in their homes in the evening time.

3) Wrong: Part time job are essential in that type of people.

Correct: Part time job is essential in that type of people.

4) Wrong: He also know the managerial rolls and regulation when he is entering in his professionals level.

Correct: He also knows the managerial rolls and regulation when he is entering in his professionals level.

5) Wrong: While others who does not work as a part time job they do not know a any kind of managerial rolls and regulation of the company or any other organization. 
Correct: While others who do not work as a part time job they do not know a any kind of managerial rolls and regulation of the company or any other organization.

6) Wrong: Part time job have many reasons.

Correct: Part time job has many reasons.

7) Wrong: Part time job is demerit that students is very tied.

Correct: Part time job is demerit that students are very tied.

8) Wrong: Now part time job have solved this problem

Correct: Now part time job has solved this problem

9) Wrong: It not only keep people busy. But also solve many inflation problems.

Correct: It not only keep people busy. But also solves many inflation problems.

10) Wrong: He want to do something for himself.

Correct: He wants to do something for himself.

11) Wrong: it is not easy to a person who have salary ten to fifteen thousand to fulfill the basic needs of his family members with out having a part time job.

Correct: it is not easy to a person who has salary ten to fifteen thousand to fulfill the basic needs of his family members with out having a part time job.

12) Wrong: He can go through his study properly when he do work in his leisure time.

Correct: He can go through his study properly when he does work in his leisure time.

13) Wrong: The student want to a money.

Correct: The student wants to a money.

14) Wrong: Part time job give a clear idea of realities of the life's work.

Correct:_Part time job gives a clear idea of realities of the life's work.

15) Wrong: Part time job give another benefit of personal experience in any particular field.

Correct: Part time job gives another benefit of personal experience in any particular field.

16) Wrong: In general part time jobs is good for students they got confidence, knowledge, experience.

Correct: In general part time jobs are good for students they got confidence, knowledge, experience.

17) Wrong: Any how, I am strongly insist that student should do part time jobs not only for themselves but also for the betterment of society.

Correct: Any how, I am strongly insisting that student should do part time jobs not only for themselves but also for the betterment of society.

18) Wrong: He do not his work at proper time.

Correct: He does not his work at proper time.

19) Wrong: It become the need of students.

Correct: It becomes the need of students.

Indefinite Pronouns Errors:

The indefinite pronoun subjects like everyone, anyone, someone, no-one, nobody are always singular and followed by singular verbs.

20) Wrong: Someone need experience of yourself.

Correct: Someone needs experience of yourself.

\section{2- Errors in subject dealings according to the given verb.}

Subject is not according to the followed verb.

1) Wrong: A person who will work in part times they are seaing

Correct: Persons who will work in part times they are seaing.

2) Wrong: In these students someone are eligible for the work and they do agood performance in the orgnazition.

Correct: In these students some are eligible for the work and they do agood performance in the orgnazition.

3) Wrong: Student find the job to share the burden of their parents.

Correct: Students find the job to share the burden of their parents.

4) Wrong: But according to my point of view a balanced students is always successful in this regard.

Correct: But according to my point of view a balanced student is always successful in this regard.

5) Wrong: College student are very busy in studies they have no time for extra activities.

Correct: College students are very busy in studies they have no time for extra activities.

6) Wrong: Their child want to study these student have no other chance.

Correct: Their children want to study these student have no other chance.

Phrasal Subject Errors:

In a phrasal subject, it is necessary that the verb must follow the main noun in the subject: 
7) Wrong: An average worker of any organization which have a big family can't survive in the society without of part time job.

Correct: An average worker of any organization which has a big family can't survive in the society without of part time job.

8) Wrong: We can say that part time job can also teach that thing how we can manage our time.

Correct: We can say that part time job can also teaches that thing how we can manage our time.

Subjects connected by 'and':

9) Wrong: In summer vocation and winter vocation student waste their time so this is benefit for them that they do part time job.

Correct: In summer vocation and winter vocation students waste their time so this is benefit for them that they do part time job.

5.3- $\quad$ Students omitted the helping verb from the sentence and also used helping verbs incorrectly.

1) Wrong: Some students have better facilities which are given by their parents they studying in better institutions.

Correct: Some students have better facilities which are given by their parents they are studying in better institutions.

2) Wrong: The college students is have a part time job.

Correct: The college students have a part time job.

1- Plural Noun Errors

Some nouns mostly used as plural and followed by plural verbs:

1) Wrong: In the part time job people gets extra money.

Correct: In the part time job people get extra money.

\section{Result and Conclusion}

The above analysis shows that the most errors occurred in 'Type 1': a singular verb occurs with a singular verb and a plural occurs with plural verb. In this type, almost 20 mistakes are found. In type 2, almost 9 mistakes have found in which students did not provide a sufficient subject which verb should follow. They used a singular subject with the plural verb and pronoun. In type 3 test, two mistakes occurred, in which Students omitted the helping verb from the sentence and also used helping verbs incorrectly. In case of plural noun errors: Some nouns mostly used as plural and followed by plural verbs, only one mistake has identified. The whole research shows that L2 learners do most mistakes of subject-verb agreement in tenses.

Type 1: $62.5 \%$

Type 2: $28 \%$

Type 3: 6.25

Type 4: $3 \%$

\section{Errors}

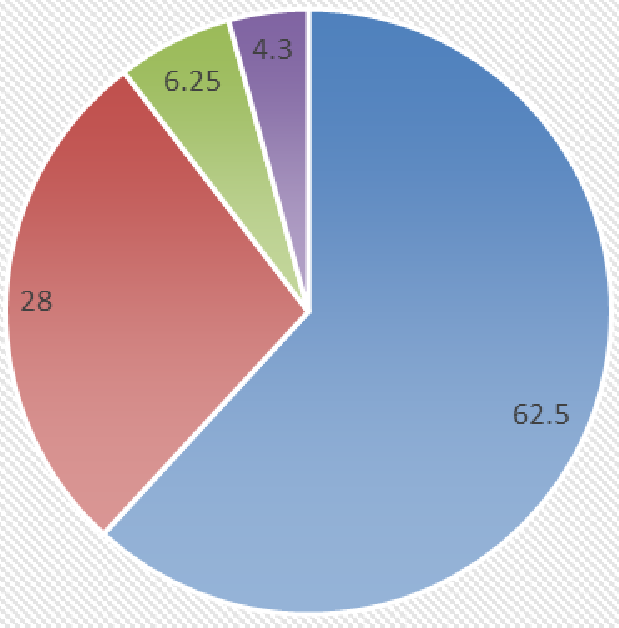




\section{Instructions}

The students do not have the sufficient knowledge about subject-verb agreement. For this purpose, the teachers should first aware them what are singular subjects and what are the plural subjects in case of nouns and pronouns and tell them about singular and plural verbs in case of main verbs and helping verbs. In essay, Students omitted the helping verb from the sentence in progressive cases. The helping verb is compulsory in progressive cases. Students also used helping verbs incorrectly in some sentences, which created difficulty in recognizing the tense of the sentence.

In present Tense Case

\begin{tabular}{|l|l|l|}
\hline & Pronouns & Verb \\
\hline Singular & He, she, It & Eat \\
\hline Plural & I, We, You, They, It & eats \\
\hline
\end{tabular}

In Present Progressive Case

\begin{tabular}{|l|l|l|l|}
\hline & Pronouns & Helping Verb & Verb \\
\hline Singular & He, she, It & Is & Eating \\
\hline Plural & I, We, You, They, It & Are & Eating \\
\hline
\end{tabular}

In present Perfect Case:

\begin{tabular}{|l|l|l|l|}
\hline & Pronouns & Helping Verb & Verb \\
\hline Singular & He, she, It & Has & Eaten \\
\hline Plural & I, We, You, They, It & have & Eaten \\
\hline
\end{tabular}

In indefinite Pronouns Case:

Some Indefinite pronouns are always singular and followed by singular verbs like everyone, anyone, someone, no-one, nobody.

E.g: No one is coming.

Someone beats me.

In phrasal subject case:

When the subject of the sentence is a phrase, the following verb must agree with the main noun in the subject."

- All members (main plural noun) of the group have (plural verb) tried to present in a keen manner.

- A white box of colors has been misplaced.

Subjects connected by 'and': In test one this type of mistake is also found.

Subjects connected by and almost form a plural subject and demand a plural verb.

- Ali and Usman (plural subject) participate (plural verb) in speech competition.

\begin{tabular}{|l|l|l|}
\hline Subject & Verb & Compliment \\
\hline Name and Name & Plural verb & \\
\hline Ali and Usman & Participate & In speech competition. \\
\hline
\end{tabular}

People is already plural subject, it does not carry plural verb. Students get confused in this plural noun.

\section{Note:}

Some other types of errors are also in extracted lines but the main focus of this research is subject-verb agreement. So, they are ignored.

Thank You.

\section{References}

- $\quad$ Elliott, R. (2015). Painless grammar. Barron's Educational Series.

- Keenan, E. L. (1976). TOHARDS A UNIVERSAI, DEFINITEON OF" SUBJECT".

- Strumpf, M., \& Douglas, A. (2004). The grammar bible: everything you always wanted to know about grammar but didn't know whom to ask. Macmillan.

- Wardhaugh, R. (1995). Understanding English Grammar: A Linguistic Approach. Blackwell Publishers, Inc., 238 Main St., 5th Floor, Cambridge, MA 02142 (hardcover: ISBN-0-631-19641-2, \$54.95; paperback: ISBN-0-631-19642-0).

- Straus, J., Kaufman, L., \& Stern, T. (2014). The blue book of grammar and punctuation: An easy-to-use guide with clear rules, real-world examples, and reproducible quizzes. John Wiley \& Sons.

- Darus, S., \& Subramaniam, K. (2009). Error analysis of the written English essays of secondary school students in Malaysia: A case study. European Journal of Social Sciences, 8(3), 483-495.

- Ascoli, S. D. (2015). A group of subject-verb agreements: Finding quantity in group and number (Doctoral dissertation, Iowa State University).

- $\quad$ Syaifurrahman, M., \& Miftah, M. Z. (2016). ERROR ANALYSIS OF SUBJECT-VERB AGREEMENT IN 
THE DIARY WRITTEN BY THE ENGLISH DEPARTMENT STUDENTS. 21st Century English Language Teaching, 82.

- Hameedullah Khan. (2017). ERRORS IN SVA AND SVO OF THE INTERMIDIATELEVEL STUDENTS.http://www.academia.edu/35694102/ERRORS_IN_SVA_AND_SVO_OF_THE_INTERMEDIA TE_LEVEL_STUDENTS.pdf

- Tafida AG, Okunade SK (2016). Subject-VerbAgreement Problem among English as Second Language Learners: A Case Study of One Hundred Level Undergraduates of Federal University of Technology, Minna. Inv. J. Edu. Gen. St. Vol.2(2):20-27

- Quirk, R. (2010). A comprehensive grammar of the English language. Pearson Education India. 